\title{
Lessons Learned From an Inside-Out Flip in Entrepreneurship Education
}

\author{
Martin J. Bliemel \\ mbliemel@unsw.edu.au \\ School of Management \\ UNSW Business School \\ UNSW Australia \\ Kensington, NSW 2052 \\ AUSTRALIA \\ Tel: +61 (0)2 93855671
}

\begin{abstract}
This paper summarizes the benefits and challenges of flipping an entrepreneurship course in two ways. The conventional flip changes how lecturers and students relate to the course content by primarily affecting when and where they learn, but not necessarily how. Flipping the classroom inside-out grounds the lessons learned in the 'real world' by bringing in guests to help run workshops in the classroom, and by getting students to validate their business ideas outside the classroom. This inside-out flip involves additional logistical challenges. However, it appears to be a better fit with the overarching set of attributes that graduates are expected to attain, and the assessment thereof.
\end{abstract}

Keywords: Flipped classroom, experiential learning, entrepreneurship education, business canvas

Pre-publication version.

Please cite as:

Bliemel, M. (2014) "Lessons from an inside-out flip in entrepreneurship education" Small Enterprise Research, 21(1) (dx.doi.org/10.1080/13215906.2014.11082080)

An earlier version of this paper also won the Best Paper award at the $27^{\text {th }}$ SEAANZ 2014: http://seaanz.org/content/images-27th-seaanz-annual-conference 


\title{
Lessons Learned From an Inside-Out Flip in Entrepreneurship Education
}

\begin{abstract}
This paper summarizes the benefits and challenges of flipping an entrepreneurship course in two ways. The conventional flip changes how lecturers and students relate to the course content by primarily affecting when and where they learn, but not necessarily how. Flipping the classroom inside-out grounds the lessons learned in the 'real world' by bringing in guests to help run workshops in the classroom, and by getting students to validate their business ideas outside the classroom. This inside-out flip involves additional logistical challenges. However, it appears to be a better fit with the overarching set of attributes that graduates are expected to attain, and the assessment thereof.
\end{abstract}

Keywords: Flipped classroom, experiential learning, entrepreneurship education, business canvas

\section{INTRODUCTION}

Entrepreneurship education (EE) is argued to be a special case of education that requires experiential components for it to be effective (e.g, Rasmussen \& Sørheim 2006; Haase \& Lautenschläger 2011; Neck \& Greene 2011; Rideout \& Gray 2013; Mason \& Arshed 2013). While the concepts are easy enough to comprehend, the real challenge resides in the 'teachability dilemma' (Haase \& Lautenschläger 2011). The dilemma is that the most relevant aspects of learning to be an entrepreneur (know-why and especially know-how), are much more difficult to teach than presenting concepts (know-what). In order to teach know-how in entrepreneurship, the conventional methods of teaching in tiered lecture theatres face significant challenges. This mode of teaching is increasingly and mockingly referred to as the 'sage on the stage' or 'chalk and talk' method of teaching, neither of which focus on whether the students have learned to apply the core concepts or become more prepared for the reality that awaits them outside the classroom.

In simple terms, for $\mathrm{EE}$ to be effective, we have to acknowledge that "experience supersedes education" (Neck \& Greene 2011, p. 56). Some argue that the impact of EE is best measured using tangible outcomes like new ventures created and their contribution to the region (see also Matlay 2001, 2006 for reviews). Whether the goal is actual entrepreneurship or education thereof, a large part of the challenge of EE is that "students have little business experience and to truly develop empathy for the entrepreneur, one must experience new venture creation before he or she can study business management or other disciplinary areas" (Neck \& Greene 2011, p. 63). Building genuine empathy for entrepreneurs is a feature of EE underscored by potential Jones, Matlay and Maritz (2012). The solution to building empathy for entrepreneurs and teaching know-how, is to get students to actually do and experience what real entrepreneurs would do, and thus internalize the know-what based on their own first-hand experience. An integral part of this solution, is expand our definition of who the stakeholders in EE are beyond the students and lecturer (e.g., as proposed by Jones \& Matlay 2011), 
There are increasing reviews about the effectiveness of EE programmess (e.g., Rasmussen \& Sørheim 2006; Pittaway \& Cope 2007; or Rideout \& Gray 2013 in a special issue dedicated to assessing the impact of EE). However, their focus on the outcomes often glosses over the pedagogical and operational details of how the programmes are taught (Vanevenhoven and Liguiri 2013; Fayolle 2013). Rare articles that summarize operational details emphasize quite different modes of experiential learning. On the one hand, we see learning by situating the students in a business, starting with site visits (Cooper, Bottomley \& Gordon 2004). On the other hand, we see learning by working on the student's own business ideas, supported by exposure to guest speakers and guidance by mentors (Haase \& Lautenschläger 2011; Bliemel 2014).

In addition to EE's emphasis on real experience or exposure to real entrepreneurs, there is a complementary trend occurring in higher education, namely the 'flipped classroom' (Bergmann \& Sams 2012). The flipped classroom (at least branded as such) was pioneered in science classes in a Colorado-based high school. As reviewed in greater detail below, the flipped classroom changes the lecturer-student relationship in context of the course materials. Instead of reviewing the course content in the classroom, and doing homework at home, the flipped mode means reviewing the course content at home (aka online) and using the classroom time to do work.

In this paper, I present a case study that describes how an entrepreneurship course was flipped, and simultaneously emphasized experiential learning. The course design draws on another emerging phenomenon: business accelerators. Business accelerators are seed stage investment deals in cohorts of ventures (Bliemel et al. 2014) that are mentored or paired with mentors by the accelerator operators. This mentoring is analogous to the flipped-class in that "to facilitate learning, the teacher's role moves from being directive to coaching, encouraging and questioning" (Draycott, Rae \& Vause 2011). Indeed, the cohort model for business accelerators was inspired by academic curriculum design ${ }^{1}$ and can readily be reapplied back to cohorts of teams in entrepreneurship courses, as shown here.

\section{BACKGROUND}

The broader context in which I present this case study is the uncertainty for higher education institutions, which are facing diminishing government support, competition from massive open online courses (MOOCs) and commercial education programs (including accelerators), and continued critique by industry about their ability to prepare students for the real world. More specifically, this case study is in an Australian university that is coming to terms with a \$2.8 billion cut to the university sector in $2013^{2}$, which in turn has been attributed to a decrease in global rankings in $2014 .^{3}$ The government's rationale is that the financial burden of higher education should be shifted more to the students. ${ }^{4}$

Meanwhile, universities around the world (including Australian ones) are investing heavily in MOOCs, which potentially undermine the university's ability to charge full tuition fees for the same course content. More specifically to entrepreneurship, privately operated

\footnotetext{
${ }^{1}$ http://ycombinator.com/start.html

${ }^{2}$ http://www.abc.net.au/news/2013-04-13/gonski/4627278

3 http://www.theaustralian.com.au/higher-education/unis-slip-further-in-global-rankings-as-funding-cuts-bite/storye6frgcjx-1226846379201\#

${ }^{4}$ http://www.theguardian.com/world/2014/may/06/university-chiefs-warn-against-cuts-to-federal-tertiary-funding
} 
organizations are emerging that focus on formal education and related programmes by which prospective entrepreneurs can develop their skills in an applied manner. ${ }^{5,6}$ Potential or current entrepreneurs now have the luxury of asking whether they want to complete a university accredited degree programme with many course work assignments that are not specific to their business idea, or to complete a shorter unaccredited programme that is designed to help them focus on their own idea. Interestingly the commercial programs are quite similar to flipped classroom approaches, and may be more economically viable (i.e., lower cost) without the overhead costs that universities face.

In recent years, industry reports calling for improvement in entrepreneurship development have either outright omitted any mention of the Australian university-based entrepreneurship education, ${ }^{7}$ or have actively criticized universities for not doing enough to prepare graduates to build technology ventures. ${ }^{8,9}$ Vice-versa, a review from the perspective of the universities is that "Overall, while Australia's universities are fairly active in teaching and researching the fields of entrepreneurship, innovation and small business, their level of engagement with SMEs remains limited and is focused on a relatively small number of institutions. In general the "hands on" engagement by academics with SMEs is not a strategic priority within most institutions” (Mazzarol 2014, p.3).

From the perspective of the students, there is an increasing appetite for becoming an entrepreneur. For example, The Kauffman foundation reports that 3.3\% of 8 million surveyed students in the US are interested in becoming entrepreneurs (Pryor \& Reedy 2009), up from $2.2 \%$ in 1993 . More extreme statistics are reported from a survey of 602 post graduate students commissioned by a bank in Canada finding that almost $50 \%$ of students are interested in becoming entrepreneurs. ${ }^{10}$ It is generally speculated that this interest in entrepreneurship is driven by the recent decrease in job security. ${ }^{11}$

Given this uncertainty from government, critique from industry, and interest from students, it is no surprise that universities are seeking out curriculum design changes with demonstrated effectiveness, such as the flipped classroom. Figuring out the financial viability of a flipped classroom approach then comes second to maintaining a relevant and effective curriculum. In the following sections, I present the design of a flipped classroom approach for one of the courses I teach, and explain how it addresses the experiential learning aspect of EE while preparing students for the 'real world.'

\footnotetext{
${ }^{5}$ http://www.startupsmart.com.au/financing-a-business/the-entourage-buys-fellow-start-up-advisory-service-mbeeducation/201108223652.html

${ }^{6}$ http://fi.co/curriculum

${ }^{7} \mathrm{http}: / / \mathrm{www} \cdot$ deloitte.com/au/siliconbeach

${ }^{8} \mathrm{http://www.digitalpulse.pwc.com.au/australian-tech-startup-ecosystem/}$

${ }^{9} \mathrm{http}: / /$ startupaus.org/crossroads/

${ }^{10} \mathrm{http} / / /$ newsroom.bmo.com/press-releases/half-of-canadian-students-aspire-to-start-their-ow-tsx-bmo201309060896440001

${ }^{11}$ http://www.ilo.org/global/research/global-reports/global-employment-trends/2014/WCMS 234107/lang-$\underline{\text { en/index.htm }}$
} 


\section{FLIPPING CLASSROOMS}

\subsection{The conventional flip: online vs in-class}

One of the primary sources for flipping classrooms is Bergmann and Sams' (2012) book, in which they summarize their ideas and observations about flipping their high-school science classes in Colorado. In their book, they suggest that the core lessons learned can be delivered before class in an online format, with preference for a short video. Students can then complete a short quiz about those lessons to make sure they are ready to do some lab exercise or other hands-on activity related to those lessons. Using this general framework, students can then focus their in-class time on doing something in the classroom other than copying notes from a whiteboard or from a PowerPoint presentation. A major advantage proposed by the authors is that students can set their own pace through the core course materials, review them as often as they like, and have immediate access to the teachers in the classroom in case they get stuck in their lab work. Their own empirical findings suggest that this enables struggling students to keep up, but not guarantee top marks for an otherwise average student.

The flip is primarily a change in what activities are done when or where: online outside of classroom hours, or in-class. It alters the relationship between the students and the teacher or lecturer in context of the course materials. However, it does not necessarily affect the relationship between the course materials and how they relate to life after completing the course.

In my adoption of the flipped classroom, I followed the general principles provided by Bergmann and Sams (2012), with a few minor customizations, as visualized in Figure 1. Instead of producing my own videos, I select publicly available ones that I believe best fit the lesson. In the area of entrepreneurship, there are frequently new videos of interviews or case studies that represent the most recent concepts. Stanford's eCorner ${ }^{12}$ has an impressive library of fully transcribed videos, which is updated regularly. In addition to the videos, I also provide some brief required readings, generally consisting of a chapter from "The Lean Startup" (Ries 2011) plus something more scientific, like a Harvard Business Review article about a similar topic. The required video and readings are then supplemented with additional online materials. By being explicit about which materials are required and which are only recommended, I avoid the confusion of what materials to focus on, as seen when I used to fit references to all these materials in the same slide deck. In an ideal scenario, all the required readings can be posted online at the beginning of the course for students to pace through at their own speed. Due to time constraints, this has not been possible, so I have uploaded links to the materials on a week by week basis.

\footnotetext{
${ }^{12}$ http://ecorner.stanford.edu/
} 


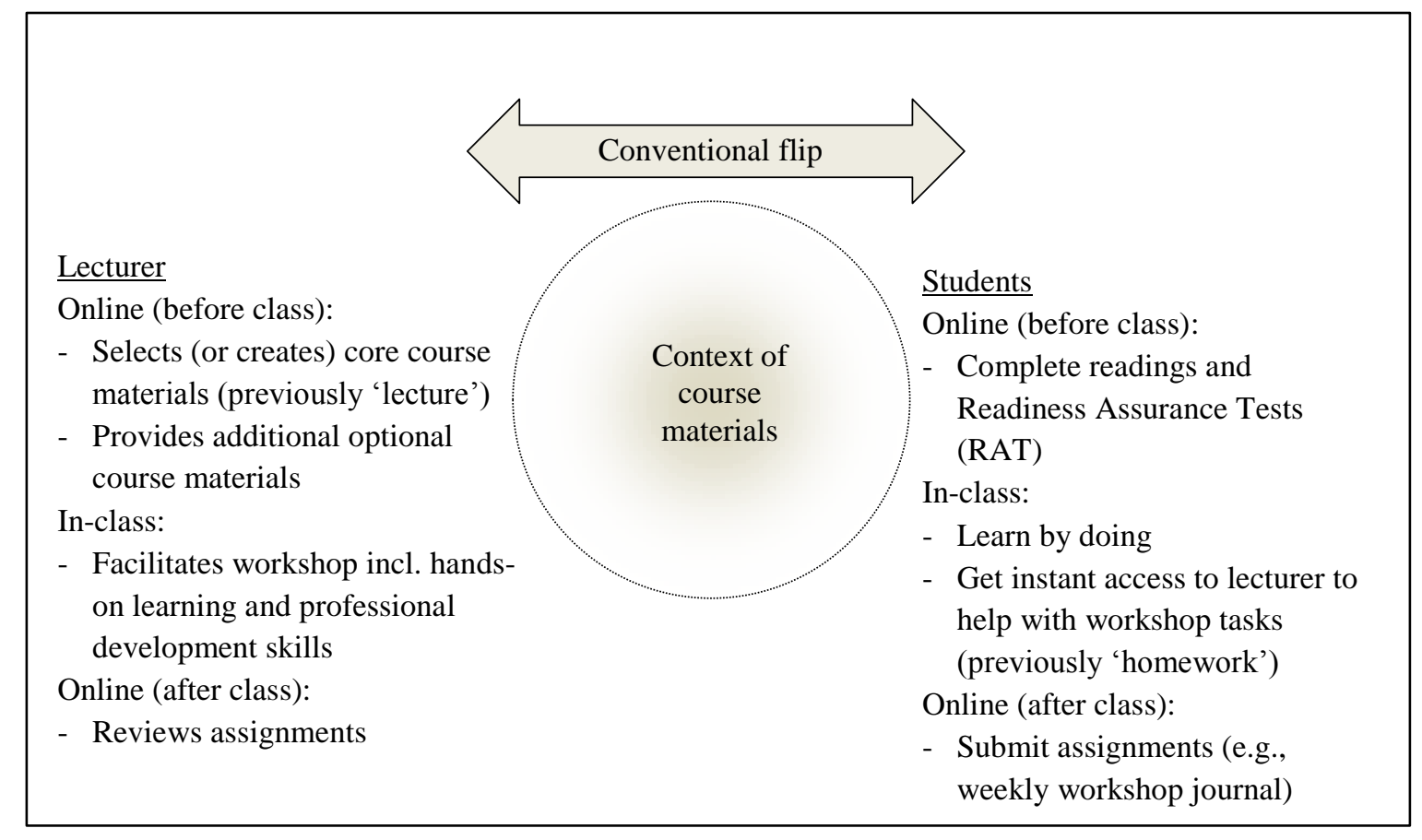

Figure 1: The conventional online/in-class flip for an entrepreneurship course

\subsection{The inside-out flip: getting real}

In addition to this (conventional) flip, I flip the classroom inside-out, as visualized in Figure 2. What I mean by an inside-out flip, is that I bring guests from industry into the classroom, and get the students to conduct part of their assignments by engaging in industry (as also advocated by Jones \& Matlay 2011). Each of these interactions with industry provides a more realistic experiential learning opportunity than in the conventional flipped classroom. The degree to which the students are immersed into the experience of being an entrepreneur varies from indirect and virtual to direct (Shepherd 2004; Bliemel 2014). Indirect experience is the experience gained by learning about entrepreneurship from guest talks. These talks may be prerecorded and online (e.g., Stanford's eCorner videos), or done live in the classroom to enable more interactive questions and answers during or after the talk. Virtual experience entails the students presenting their (virtual) business ideas to a live panel of judges in the classroom, who provide feedback to the students. Their feedback usually forms the basis for assessing the academic performance of the each team of students. These experiences are virtual in that the business idea development is primarily an academic exercise, and not (yet) intended to be a real business. Lastly, direct experience entails the students talking to real people about their business idea, in order to validate their assumptions. These validation tests are generally outside of class, off campus, and done with potential customers, suppliers, competitors, partners, regulators and investors. These are direct experiences because they reflect exactly what real entrepreneurs do. 


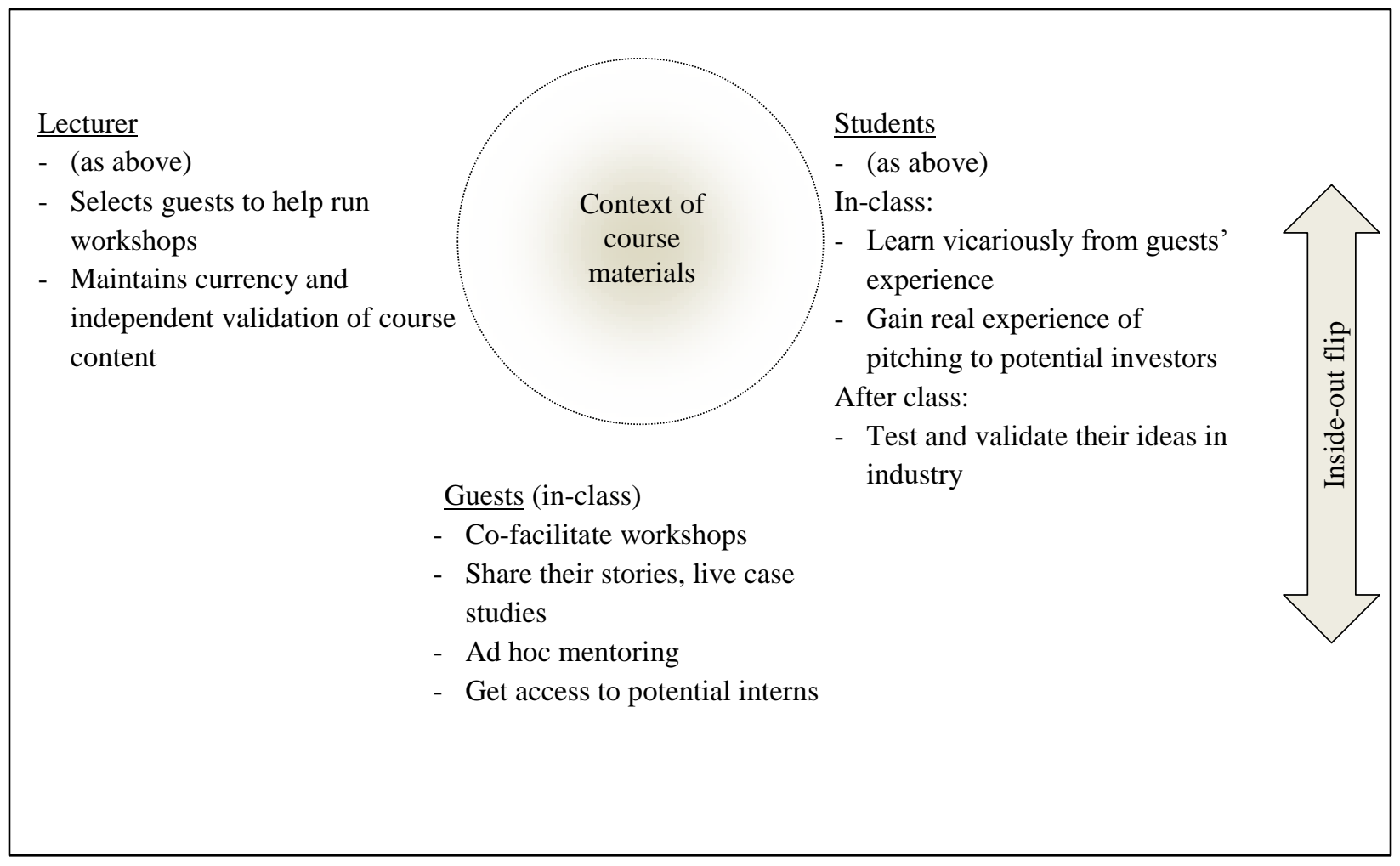

Figure 2: Flipping an entrepreneurship course inside-out

The inside-out flip can be done separately to the conventional flip (e.g., as previously done in my course, see Bliemel 2014 for details). However, both flips complement each other because they focus more attention on getting high quality feedback to the students about their projects. The conventional flip enables higher quality feedback in-class, and the inside-out flip enables higher quality feedback outside of class. In the following sections, I review the current curriculum design, how it is flipped, and identify opportunities to reevaluate how this design fits with the program learning goals and outcomes.

\section{CASE STUDY}

This course takes inspiration from the programmes offered by business accelerators. Accelerators are programmes that (i) accept cohorts of teams of entrepreneurs to spend 4-12 months in the same space to develop their ventures, and (ii) gives them all the same standard seed capital terms. Teams are provided a pool of mentors, many of whom have invested in the fund that provides the seed capital for the cohort. By operating a cohort-based model and co-locating teams, participants can learn directly from each other (e.g., Grimaldi \& Grandi 2005; Malek et al. 2013). Such knowledge spillovers are usually not common or possible with conventional (ad hoc) seed investment deals. Throughout the duration of the accelerator programme, teams work on validating the customer and the market, and then advance to validating the technology, scalability and financial viability. Both of these phases are highly iterative and follow cycles of evidence-based learning. A common tool to use with which to articulate the business model and 
track its evolution over time is the Business Canvas, which can be monitored using commercially available tools such as Launchpad Central. ${ }^{13}$

\subsection{Conventional flip: Pre-class (online)}

To accomplish the conventional flip, I provided required and recommended readings online, in advance of every session (they are no longer called "lectures"). I use two methods to make sure students have completed the readings and come to class prepared, and two methods to make sure teams have developed their business models in between sessions. The first method at the individual level is the Readiness Assurance Test (RAT, common in medical education). Students are given a 2-hour window to complete a 5-minute multiple choice quiz related to the core readings. Each student is given a random sample of 3 out of 10 multiple choice questions related to the readings. This way, students can even conduct the quiz seated next to each other without being able to be of significant assistance. If they do help each other, then I see this as peer learning, not cheating. They may even repeat the quiz (with a new set of 3 questions) within the 5 minute timeframe if they are unhappy with the results of their first attempt, and want the best marks across attempts. The drawback is that they may not complete subsequent iterations due to the time limit. RAT scores are linked to the final grades.

The second method to keep students up to speed on the readings for each session resides in the peer pressure and peer assessment from team mates. If a student shows up unprepared, then the other team mates can encourage the student to pick up the slack and not hold back the team's progress in the workshop related to the readings. At the mid-term and end of the course, students anonymously assess each other using the WebPA tool. ${ }^{14}$ WebPA scores are linked to the final grades. This provides another avenue for students to use anonymous peer pressure at the mid-term to let lagging students know they are not meeting the team's expectations or to reward leaders.

At the team level the methods are relatively similar to the individual level. Teams are asked to upload their latest business canvas to the course website (currently using moodle's database too ${ }^{15}$ ). Each canvas is accompanied with a mention of which business model hypotheses were tested in the previous week, how they were tested, what the outcome was (validation or invalidation), and how this outcome affected their canvas. Teams are also asked to mention which hypotheses they have generated, to be tested in the following week. Business canvas uploads are linked to the final grades and are be graded for quality, completeness and evidence of learning.

The second team-level method to keep teams performing is peer pressure across teams. This is facilitated in two ways. Counts of hypotheses tested and generated are used to create a "Leaderboard" for all teams to see and aspire to attain top rankings. ${ }^{16}$ To balance the crudeness of these rankings, I also ask each team to give a brief (1-2 minute) update pitch about how their business model has evolved. These pitches are done at the beginning of each session. By having

\footnotetext{
${ }^{13}$ www.launchpadcentral.com

14 http://sourceforge.net/projects/webpa/

$15 \mathrm{http://docs.moodle.org/26/en/Database} \mathrm{activity} \mathrm{module}$

$16 \underline{\mathrm{http}: / / \text { steveblank.com/2013/11/25/its-time-to-play-moneyball-the-investment-readiness-level/ }}$
} 
all teams see each other's update pitches, they can also learn from each other and pick up ideas on how to test different hypotheses.

\subsection{Conventional Flip: In-class}

By providing and testing for the core course content online before class, this frees up the in-class time to be more hands on. Instead of running 1.5 hour lectures with dozens of slides, followed later by a separate session of similar length, I now have 3 hours of continuous time to work with. This allows for teams to dig deeper into their ideas and get meaningful amounts of work done, instead of trying to pack the set-up of the workshop, the workshop itself, and its debrief into less than 90 minutes.

During the 'free time' for students to work in their teams, I (and available guests) rotate from table to table to answer any questions that they have. It is not uncommon for teams to use this time to work on multiple aspects of their business idea simultaneously, including modifying their website, editing their product demo video, updating their financial model, etc. By having this time in the regular teaching hours, teams also do not have to spend excessive amounts of time to coordinate time to meet outside of class (a challenge for courses in which students are from all faculties). Once they have gotten another round of work done as a team, they can also more easily allocate additional tasks to be completed outside of class.

\subsection{Inside-out flip: In-class}

The in-class time invites opportunities for students to interact with guests who can reinforce that the core lessons students are learning are not just theoretical exercises. In some sessions, I draw on guest speakers to talk about their new ventures, but try and limit the duration of the talk to less than 1 hour to preserve the time available for students to work together. Guest speakers have so far expressed great enthusiasm for being able to walk from team to team after their talk, to learn about each team's project and assist them in a more meaningful way than the conventional post-talk Q\&A.

In other sessions, the guest co-facilitates a workshop related to the core learnings for the week. For example, a recent design thinking workshop asked each team to generate multiple user profiles to help them focus on who specifically their target customers area. This was then followed by creating "journey maps" for a lead-user, innovator or early adopter of their choice, to think through the steps by which the user discovered the product (or service), learned more about the product to make an informed decision to buy it, bought it, received customer support, used the product, and disposed of the product.

The guests general reinforce the core materials by demonstrating that real entrepreneurs also care about attempting to control their immediate future (aka effectuation theory; Sarasvathy 2001), financial modeling and valuations, mentors, statistics on business failures (e.g., Fisher and Reuber 2010), angel and venture capital investing ${ }^{17}$ (e.g., Ramadani 2009), diffusion of innovation (Bass 1969; Rogers 2003; Shim \& Bliemel 2013), global trade network evolution (e.g., Serrano, Boguñá and Vespignani 2007), the lean canvas (Maurya 2012), the strategy canvas (Kim and Mauborgne 2005), Product-Customer-Matrix (Boardman \& Vining 1996),

\footnotetext{
${ }^{17} \mathrm{http} / / / \mathrm{www}$. slideshare.net/proto1234/the-future-of-venture-capital-in-australia-14202296
} 
Gartner's Hype Cycle ${ }^{18}$, disruptive innovation (Bower and Christensen 1995), open innovation (Chesbrough 2003), and serendipity (Dew 2009; Bliemel 2013). Learning from guests in the course constitutes one form of indirect experiential learning (Shepherd 2004; Bliemel 2014), because they are learning about entrepreneurship from someone else's direct experience.

Students may also receive virtual experience via guests from industry in the form of informal feedback and formal feedback. Informal feedback occurs when guests co-facilitate workshops and join me in rotating from table to table to help students make progress with their ideas. Formal feedback occurs during the final Demo Day, where teams pitch their business ideas in a competitive manner. These final pitches are much like real pitch competitions that occur at industry events. Judges for the pitches in the course usually do not treat the students' pitches any differently than they would a pitch at an industry event. These experiences are virtual for the students in that they are (usually) not for a real business idea they intend to pursue after the course. That said, on occasion some students do continue executing their course project as a real business, even though they did not have such an intention during the course, thus blurring the distinction between virtual and real experience.

\subsection{Inside-out flip: Outside of class}

The activities done by students outside the inside-out flipped classroom transform homework into fieldwork. The process of going out into the field (i.e. talking to people outside the university) resonates with the 'genchi gembutsu' principle that was adopted by The Lean Startup (Ries 2011) and is one of the 14 core principles of The Toyota Way (Liker 2003). The principle asks entrepreneurs to challenge what they believe they know about the customer, supplier, investor, or any other stakeholder, and find out first-hand what the situation is. As described by Liker (2003): "You cannot be sure you really understand any part of any business problem unless you go and see for yourself firsthand. It is unacceptable to take anything for granted or to rely on the reports of others" (p. 233). The process of collecting field data with which to validate their business ideas is perhaps the single most effective way for students to build empathy for what it is like to be an entrepreneur, thus addressing Neck and Greene (2011) and Jones, Matlay and Maritz's (2012) calls.

As their first assignment, and in order to get the comfortable talking about entrepreneurship to others outside the course, each student is asked to contact an entrepreneur and interview them about their business. The definition of entrepreneur for this exercise is deliberately broad to include anyone who has set up their own business, and not limited to the Richard Bransons and Elon Musks that draw so much media attention to the word 'entrepreneur'. Completing the interview is linked to the final grades. This exercise is primarily an indirect experience, because the student is learning about entrepreneurship from the perspective of the person they interview, while also gaining the direct experience of conducting field work.

Following a similar format to finding and interviewing an entrepreneur, teams of students are asked to find a mentor for their team. Finding a mentor is linked to the final grades, and students are encouraged to interview their mentor for extra experience. In many cases, one of the entrepreneurs they interviewed becomes the team's mentor for the duration of the semester. If teams struggle to find a mentor, a mentor from a prior cohort may be matched with the team.

${ }^{18}$ http://www.gartner.com/technology/research/methodologies/hype-cycle.jsp 
Depending on the feedback from their mentor, this experience can be indirect (leveraging lessons learned by the mentor), virtual (simulating a relationship between a founding team and their board of advisors), or even real (if the team is actually intending to proceed with the idea after the course).

Perhaps the most important experience in the course is the process of (repeatedly) testing hypotheses about the business model in industry. Urged on by the regular business canvas update assignment, and often also by the mentors and guest speakers, students experience the same firsthand market research experience as entrepreneurs. Here, too, the distinction between virtual and real experience is blurred. Over the duration of the course, the students conduct (more or less structured) interviews with real potential customers, suppliers, partners, investors, and other external stakeholders. Teams usually approach external stakeholders by declaring that they are doing market research for a course project. This usually then triggers a favorable response, because of the goodwill of others to help students learn. In other cases, the response is tentative and some advice or resources are intentionally and explicitly withheld unless the students actually intend to pursue the business.

Once they think they know what data they are looking for, students often turn to online surveys to collect larger volumes of structured data for quantitative analysis. Partway through the course, students are also required to create a simple website, with which to test hypotheses about what features different customers are interested in, and to think more concretely about the marketing and sales process. For the most part, the surveys and website traffic are due to them asking their friends to participate (e.g., via facebook) and not entirely representative of their intended target market. Despite the sometimes questionable accuracy of the feedback, the lessons learned from these interviews, surveys, and website traffic are often neatly summarized in the business canvas updates, as evidence that the students are learning (about) entrepreneurship.

\subsection{Alignment with Program Learning Goals and Outcomes}

In this section, I take a critical look at the standard Program Learning Goals and Outcomes (PLG\&O) that are embedded into every course outline in my faculty and compare them against aspects of the flipped classroom, as presented here.

1. Knowledge: Our graduates will have in-depth disciplinary knowledge applicable in local and global contexts

Whether students have "in-depth disciplinary knowledge" is a fair question. However, whether or not they know how to apply that knowledge in various contexts is hard to assess if it is only applied in the classroom. By basing some of the students' grades on their ability to validate their ideas outside the classroom, it becomes easier to evaluate this item in its entirety.

2. Critical thinking and problem solving: Our graduates will be critical thinkers and effective problem solvers.

The critical thinking aspect is relatively straightforward to observe in each team's comments about the hypotheses they tested and generated. Since the purpose of the business is to solve a customer's problem, then the (potential or actually served) customers themselves are the best judges of whether the solution is effective. 
3. Communication: Our graduates will be effective professional communicators.

Using the methods outlined above, the graduates are pushed to learn to communicate professionally with several different kinds of stakeholders that any real entrepreneur deals with on a regular basis. Since most students are still novices at professional communication, there are limits in terms of how much professionalism they can learn from presenting to each other using only the conventional teaching methods. Like most professionals, students in this course are also learning to communicate using multiple modes, including by phone, email, videos, and live presentations. Here too, the effectiveness aspect is best assessed by the intended audience of their message, which is then reflected in their notes about hypotheses they have tested with those audiences.

4. Teamwork: Our graduates will be effective team participants.

The effectiveness aspect may refer to the effectiveness within a team, not just the effectiveness of a team. The effectiveness of their participation within a team is best assessed by their peers, and is captured using the WebPA system, and also the in-class team dynamics. The effectiveness of the team is reflected in their various group assignments.

5. Ethical, social and environmental responsibility: Our graduates will have a sound awareness of the ethical, social, cultural and environmental implications of business practice.

Having awareness of these responsibilities is not the same as effectively demonstrating them. While it may not suit every team's business idea, some teams associate their product with responsible organizations in order to increase the legitimacy and attractiveness of their venture. For instance, a team with an idea related to swimming pool maintenance and equipment recently gained buy-in by the founder Kids Alive ${ }^{19}$ to associate their service with lowering the chances of drowning for children.

Overall, while we lecturers may be subject matter experts of the content being taught, we are not necessarily the best judges of whether the students have translated this content into knowledge in a way that prepares them for graduation. Instead of being the only judge of their abilities, this critique suggests that external stakeholders may be better judges, or at least be critical informants for us to make a final judgment. These external stakeholders can be engaged throughout the course by flipping the classroom inside-out.

\section{IMPLICATIONS FOR PRACTICE}

Flipping the classroom has clear implications for the practice of teaching. In the conventional flipped classroom, less emphasis is placed on the lecturer as the 'sage on the stage', and more as the 'guide by your side.' This means that for this method of teaching to be effective, lecturers may need to learn to give up control of what happens in the classroom, and redirect their attention towards the development of soft-skills (the latter is also echoed by Haase \& Lautenschläger 2011).

Flipping the classroom inside-out means giving up even more control. While the lecturer has some say in the design of workshops that are co-facilitated by guests, assuming too much

${ }^{19}$ http://www.kidsalive.com.au/ 
control over them will turn off guests from participating again. The lecturer has even less control over what happens outside the classroom as each team validates their ideas in situ. In this case, the shift in attention is from directly judging the students, to judging their performance based on other's reports of their effectiveness. In some cases these reports are generated by the students (e.g., the business canvas uploads), and in other cases the reports are from the external guests who come to attend the final demo day.

\section{LIMITATIONS AND OPPORTUNITIES FOR EXTENSIONS:}

The largest limitation of this study is that the methods presented here are still only rough field notes from a recent curriculum redesign. The effectiveness of each form of flipping remains to be tested by more rigorous research. Such research would probably involve longitudinal observations, and ideally include comparison of cohorts that have been flipped differently (if flipped at all).

Assessing the effectiveness of EE has the unique challenge of figuring out whether academic marks in the course actually matter. Will the most entrepreneurial students drop out to pursue their business ideas? Will they focus more on the effectiveness of their venture than their grades? By aligning the coursework assessments with the effectiveness of the venture, there is hope that the latter question becomes irrelevant.

In terms of opportunities for extending the flipped classroom, several avenues are possible. On the one hand, the experience may become more immersive and more direct, such as internship placements in new ventures and other forms of work integrated learning. On the other hand, the experience may become more virtual if the course is redesigned to become more like a MOOC. Such a virtualization is conceivable if more emphasis is placed on the business canvas uploads, and the in-class activities are moved online or removed entirely. For example, the update pitches could be eliminated, at the risk of limiting the ability of teams to learn from each other. Or, the guest talks could be replaced by online talks, at the risk of losing the interaction from the Q\&A. Or, the workshops could be turned (back) into homework, at the risk of not being able to immediately assist teams that have questions.

An additional opportunity for extension is in gamification. While the leaderboards already create some semi-public rankings, other aspects of the course can be turned into challenges for which teams can earn badges and bragging rights. For example, awards may be given to teams that have interviewed or surveyed a minimum number of potential customers. Or, only the first team to cross this threshold may win that badge. The opportunities to give (and lose) awards are as endless as the plethora of reality TV shows that use similar methods (e.g., immunity, life-lines, etc.).

\section{CONCLUSION}

This case study has presented two different ways in which classrooms in EE can be flipped (conventional and inside-out), and presented some operational details about how an entrepreneurship course was flipped both ways. In doing so, I have elaborated on aspects of the course according to when and where they occur (in-class, online, outside the class) and identified their level of experiential learning (indirect, virtual or direct). I have also provided a critical review of the Program Learning Goals and Outcomes that describe what graduates are expected 
to have, do, or be. This critical review emphasizes a component of experiential learning in EE that has probably remained underemphasized in the literature: assessment of whether the students' learning entrepreneurship (not just about entrepreneurship) can be improved by drawing on feedback from industry about the students' activities.

\section{REFERENCES}

Bass, F (1969) A new product growth model for consumer durables. Management Sciences 15(5), 215-227.

Bergmann, J \& Sams A (2012) Flip your classroom: talk to every student in every class every day. International Society for Technology in Education.

Bliemel MJ (2014) Getting entrepreneurship education out of the classroom and into students' heads. Entrepreneurship Research Journal, 4(2), 237-260.

Bliemel, MJ, Flores, R, Hamilius, J \& Gomes, H (2014) Accelerate Australia far: Exploring the emergence of seed accelerators within the innovation ecosystem down-under. Australian Centre for Entrepreneurship Research Exchange, February 4-7, 2013, Sydney, NSW.

Bliemel, MJ (2013) On the resource foundations and triggers of lucky events. Australian Centre for Entrepreneurship Research Exchange, Brisbane, QLD, February 6-8, 2013.

Boardman, AE \& Vining, AR (1996) Defining your business using product-customer matrices. Long Range Planning, 29(1), 38-48.

Bower, JL \& Christensen, CM (1995) Disruptive technologies: Catching the wave. Harvard Business Review, 73(1), 43-53.

Chesbrough, H (2003) Open innovation: The new imperative for creating and profiting from technology. Harvard Business School Press, Cambridge, MA.

Cooper, S, Bottomley, C \& Gordon, J (2004) Stepping out of the classroom and up the ladder of learning: An experiential learning approach to entrepreneurship education. Industry and Higher Education, 18(1), 11-22.

Dew, N (2009) Serendipity in entrepreneurship. Organization Studies, 30(7), 735-753.

Draycott, M. C., Rae, D., \& Vause, K. (2011) The assessment of enterprise education in the secondary education sector: A new approach? Education + Training, 53(8/9), 673-691.

Fayolle, A (2013) Personal views on the future of entrepreneurship education. Entrepreneurship \& Regional Development, 25(7-8), 692-701.

Fisher, E \& Reuber, R (2010) The state of entrepreneurship in Canada. Industry Canada, accessed October 1, 2011, http://www.ic.gc.ca/eic/site/061.nsf/eng/h_rd02468.html

Grimaldi, R, \& Grandi, A (2005) Business incubators and new venture creation: an assessment of incubating models. Technovation, 25(2), 111-121.

Haase, H \& Lautenschläger A (2011) The 'teachability dilemma' of entrepreneurship. International Entrepreneurship and Management Journal, 7(2), 145-162.

Jones, C., \& Matlay, H. (2011) Understanding the heterogeneity of entrepreneurship education: going beyond Gartner. Education + Training, 53(8/9), 692-703.

Jones, C., Matlay, H., \& Maritz, A. (2012) Enterprise education: for all, or just some? Education + Training, 54(8/9), 813-824.

Kim, WC \& Mauborgne, R (2005) Blue ocean strategy: From theory to practice. California Management Review 47(3), 105-121.

Liker, JK (2003) The Toyota Way: 14 management principles from the world's greatest manufacturer. New York: McGraw-Hill. 
Malek, K, Maine, EMA, \& McCarthy, IP (2013) A typology of clean technology commercialization accelerators. Journal of Engineering and Technology Management, in press, corrected proof

Mason, C., \& Arshed, N. (2013) Teaching entrepreneurship to university students through experiential learning: A case study. Industry and Higher Education, 27(6), 449-463.

Matlay, H. (2001) Entrepreneurial and vocational education and training in central and Eastern Europe. Education + Training, 43(8/9), 395-404.

Matlay, H. (2006). Researching entrepreneurship and education: Part 2: What is entrepreneurship education and does it matter? Education + Training, 48(8/9), 704-718.

Maurya, A (2012) Running lean: Iterate from plan A to a plan that works. O'Reilly Media.

Mazzarol, T (2014) How do Australia's universities engage with entrepreneurship and small business? Centre for Entrepreneurial Management and Innovation (CEMI) Discussion Paper No. 1401. Available at SSRN: http://ssrn.com/abstract=2428008

Neck, HM \& Greene, PG (2011) Entrepreneurship education: known worlds and new frontiers. Journal of Small Business Management, 49(1), 55-70.

Pittaway, L \& Cope, J (2007) Entrepreneurship education: A systematic review of the evidence. International Small Business Journal, 25(5), 479-510.

Pryor, JH \& Reedy, EJ (2009) Trends in business interest among U.S. college students: An early exploration of data available from the Cooperative Institutional Research Program. Available at SSRN: http://ssrn.com/abstract=1971393

Ramadani, V (2009) Business angels: Who they really are. Strategic Change, 18(7-8), 249-258.

Rasmussen, EA \& Sørheim S (2006) Action-based entrepreneurship education', Technovation, 26(2), 185-194.

Rideout, EC \& Gray DO (2013) Does entrepreneurship education really work? A review and methodological critique of the empirical literature on the effects of university-based entrepreneurship education. Journal of Small Business Management, 51(3), 329-351.

Ries, E (2011) The lean startup: How today's entrepreneurs use continuous innovation to create radically successful businesses. New York: Crown Business.

Rogers, E (2003) Diffusion of innovations (5th ed.). New York: Free Press.

Sarasvathy, SD (2001) Causation and effectuation: Toward a theoretical shift from economic inevitability to entrepreneurial contingency. Academy of Management Review, 26(2), 243-263.

Serrano, MA, Boguñá, M \& Vespignani, A (2007) Patterns of dominant flows in the world trade web. Journal of Economic Interaction and Coordination, 2(2), 111-124.

Shepherd, DA (2004) Educating entrepreneurship students about emotion and learning from failure. Academy of Management Learning \& Education, 3(3), 274-287.

Shim, J \& Bliemel, MJ (2013) How can we predict the performance of small firms' online advertising? An agent-based modelling \& simulation approach. In 26th Annual SEAANZ Conference Proceedings, Sydney, Australia.

Vanevenhoven, J \& Liguori E (2013) The impact of entrepreneurship education: Introducing the entrepreneurship education project. Journal of Small Business Management, 51(3), 315328. 